Research Article

\title{
Organizational Structure Differentiation and Evolution of International Corporations Based on Company-Atom Analogy in the Mobile Internet Era
}

\author{
Kun Shi (iD \\ School of Business Administration, Shanghai Lixin University of Accounting and Finance, Shanghai 201620, China \\ Correspondence should be addressed to Kun Shi; shikun@lixin.edu.cn
}

Received 23 August 2021; Accepted 7 September 2021; Published 4 October 2021

Academic Editor: Sang-Bing Tsai

Copyright (c) 2021 Kun Shi. This is an open access article distributed under the Creative Commons Attribution License, which permits unrestricted use, distribution, and reproduction in any medium, provided the original work is properly cited.

\begin{abstract}
It goes without saying that people play a critical and active role in economic activity, and humans are the fundamental unit of companies in the global economy, in which organizational changes have occurred in the emerging mobile Internet era. This paper aims to establish a theoretical model of analogy between companies and atoms to study the differentiation and evolution of the recent international expansion of corporations. It fulfills a comparative study of what leads to organizational change and how it is influenced by economic activity from an interdisciplinary perspective. An exploratory study was made to evaluate economic activity in relation to quantum mechanics theory, clarify the organizational structure according to the electron cloud model, elaborate on the evolution of the expanding organizational structure by referring to the periodic table, and develop an insight into sustainability for economic globalization. It reveals that sustainable economic globalization may rely on the global values of connecting and sharing with information systems in the mobile Internet era, along with organizational evolution. Global sustainability depends on economic development achieving a balance with resource constraints and population growth.
\end{abstract}

\section{Introduction}

In the twenty-first century, mobile devices have drastically changed how people use the Internet, leading to dramatic social changes. People are now living in a smarter stage of civilization with improved information systems, with information acquired and sent easily and quickly, especially in so-called modern smart cities. Social changes occur when more valuable information on public opinions can be gained, with mobile technology development showing better public governance [1]. The change also influences the domains of civil engineering and critical infrastructure, playing the role of master designer, steward, innovator, integrator, manager of risk, leader, and also decision-maker to improve the management process [2]. Information acquisition and processing lead to a change in human behavior and mentality, driving deep changes in daily life and also work.

In the field of business management, mobile Internet technologies have an even greater impact on entities and enterprises, especially international companies that embrace economic globalization, due to the internet-related characteristics of global connectivity and flexibility. Digital media platforms have revolutionized marketing [3], and mobile applications are offering new ways to reach, communicate with, and provide services to customers. Some recent studies have discussed such emerging perspectives as viral marketing [4] and consumer behavior [5]. Changes have also occurred in operation processes as technology innovations have begun to leverage the execution of stakeholder values and influence operations management $[6,7]$. The term "mobile enterprise" has emerged, which describes an enterprise managed through specific management activities within the conversion process, use process, and competitive process [8].

At the beginning of the era of the mobile Internet, a major structural design challenge was to maintain the employees' connection to the organization. Verbeke [9] highlighted that the coevolution of the governance structure 
of a multinational enterprise (MNE) and its technological competencies determines future strategy choices. More recently, the emerging self-media (we-media) age has demonstrated the impacts that self-expression, self-creativity, and self-performance all have on society and economy with new mobile technology and infrastructure conditions available to people all over the world, especially when facing COVID-19 challenge with limited social contact. It is a powerful and influential experience that a large population, without geographical or organizational constraints and naturally international, are free to express themselves through digital media. At the same time, some emerging signs have shown that workplace employees are connecting remotely to companies, corporations, or any organization worldwide. This has led to the challenge of existing organizational theories of characteristics of general management principles of a rigid hierarchy and command, replacing it with a looser, dispersed structure that is self-organized and provides a motivating working experience in a boundaryless organization.

One of the basic functions of management is organizing; thus, organizational theories mainly focus on the structural design and adaption of a company. However, due to the increasing complexity of multinational corporations, the organizational structure has become an important aspect of the series.

The foundations of modern business theory still possess a relatively micro-organizational view and are based on the fundamental fact that humans play a critically active and subjective role in a company, being the main behavioral agent of trade and transactions in product manufacturing or service provision. In a brief model of the trade value chain, local companies exploit resources, manufacture goods, then sell goods or provide services, and finally gain profits to continually expand their business. As for cross-border business, trade is a primary way of internationalization according to the ownership, location, internalization (OLI) model developed by John Dunning [10-12]. It emphasizes the motivations of ownership, location, and internalization [13-16] in the framework of a multinational company. Stopford and Wells [17] analyzed the evolving structure responding to the function of international trade by foreign sales and product diversity, while Bartlett [18] developed his physiological model theory using anatomy, physiology, and psychology to conceptualize the array of tools and the process. Informal structure theories [19] with complicated MNEs did not cover the fact that companies survived and operated to be sustainable, organic, or viable structures and were dependent on people in the view of organizational ecology studies $[20,21]$. Human society lies within millions of entities such as nodes, forming economic value chains and combining them to become social networks, together with economic ecology. Riviere [22] theorized that MNEs could adapt to environmental changes by reconciling the routine reconfiguration of the headquarters and regional offices with dynamic capability development. Despite the complicated traditional business structure above, Dunning [23] also put forward the view that the contemporary network MNE might be a coordinator of a global system of value-added activities, but its management was still controlled. Cantwell [24] highlighted that human innovation from both firmlevel creativity and institutional entrepreneurship might lead to coevolution with the environment. However, in the recent decades of ever-changing mobile Internet business, several new studies have shown that new information technology improves organizational performance, resulting in positive changes and growth in organizations [25]. Other studies have also shown that firms now use extensive mobile organizational devices instead of visible working areas, showing the flexibility to form digital business networks [26]. However, few studies have focused on the everlasting description and intrinsic mechanism of organizational evolution theory.

To describe this evolving situation of organizational structure in the new era, a model of interdisciplinary organizational analogy between the company and the atom was established to study the differences and the evolution process from the entrepreneurial to the bureaucratic stage. There was a particular focus on the expansion of small businesses to become international corporations and also on the original mechanism with generally visualized similarity in the background of this emerging but sustainable globalized digitalization. Firstly, it started with the similarity of humans in societies and electrons in atoms given quantization and organizational ecology, providing an innovative notion that the human was the basic unit for a company and influenced the structural organization of managerial modes and possibly the same from companies to the global economy as basic units to the whole. Secondly, the proposed analogy was followed by a brief electron cloud model introduction to explain the description of the structural evolution. After that, a comparison was made of the different structural modes and combinations of humans that led to the differentiation of corporate organizations. This was termed the company-atom analogy, in which the mechanism and structure of an atom with electrons were also applied to a company with people. Interdisciplinary concepts from chemistry (defined by Simpson and Weiner, 1989) [27] and quantum mechanics (defined by Born, 1989) [28] in natural science were referred to in this study. Finally, the structural evolution process was discussed and, using the company as an atom to form a global economy, led to the conclusion that sharing worldwide is of great importance in the Internet era.

\section{Human-Electron Analogy}

Economic activities exist in human society and depend deeply on human behavior. It is people who make the society of each nation sentient, sustainable, and specific. Meanwhile, there is also a substance that commonly exists in organisms in the natural world, of which the entire global ecological system is composed, together with inorganic factors.

An organism is any living structure capable of growth and biological reproduction. What differentiate these organisms are the different combinations of structures made from amino acids, carbohydrates, and lipids, which are all vital for life. But Shi [29] argued that the core factors of life within these three classes of biochemical molecules are 
electrons, as electrons make physiological reactions possible, compose bioactive structures, and perform substantial biochemical functions. This theory can also be applied to human civilization. brief.

The human-electron analogy is listed in the following in

Both human and electron are the basic factors of any organization and are widely distributed, whether in human society or the natural world. Despite having various colors, structures, or behaviors for every species of organism or religion, culture, or class for human nations and civilizations, they are essentially the basic units and can almost be considered equal to some extent.

Both human and electron are active and willing to move from one position to another and make that change with natural liquidity. A chemical reaction occurs by electronic transition among atoms, while deals and transactions are to exchange values. All of history is driven by people's choices and desires, and historically, most human migration has promoted the progress of human civilization.

Both human and electron are responsible for the survival, viability, sustainability, and evolution of an organization. Electron flow implies energy change within a living organism, and companies are always operated by managers and also employees. Cities rise due to immigration, while civilizations decline and even fall with a decreasing human population.

Therefore, the human-atom analogy is the main focus of the model discussed below.

\section{Electron Cloud Model}

In physics, the electron cloud model is the established model of an atom, which helps visualize the most probable position of electrons in an atom-based structure and describe where electrons are while they float around the nucleus. This model does not try to explain exactly where an electron is at any given time, but that the electrons are more likely to be in specific areas. The only certainty is the uncertainty above.

In theoretical physics, an orbital wave function for atoms is a single coordinate:

$$
\psi(r, \theta, \varphi)=R(r) \Theta(\theta) \Phi(\varphi) .
$$

It is widely accepted that the angular factors of atomic orbitals $\Theta(\theta) \Phi(\varphi)$ generate $s, p, d, f$, and so on functions as real combinations of spherical harmonics $Y_{\ell m}(\theta, \varphi)$, and the radial functions $R(r)$ typically have three mathematical forms.

The electron is the basic unit of a chemical reaction, but its position varies within a complicated mechanism. The electrons occupy a series of layers called electron shells (numbered shell 1, shell 2, and so on) in the classic physical model. In the periodic table, neutral atoms show a recurring periodicity, and chemical elements are ordered according to their atomic number and the electron configuration orbiting the nucleus. Each electron shell consists of one or more subshells (named $s, p, d, f$, and $g$ ). As the atomic number increases, electrons fill these shells and subshells progressively with a number identical to the number of protons according to the energy ordering rule. So in the electron cloud model above, real combinations of spherical harmonics $Y_{\ell m}(\theta, \varphi)$ (where $\ell$ and $m$ are quantum numbers) are used to figure out the structure and characteristics of different electrons orbiting as $1 s^{2}, 2 s^{2}, 2 p^{6}, 3 s^{2}, 3 p^{6}$, and so on.

These forms will help explain the company model, which is explained below.

\section{Human Structure of Company: Differentiation}

4.1. Domestic Company: Factory and Worker. Traditionally, management theories are derived from the practice of owner and labor, in which workers are employed for an internal manufacturing process or an external marketing service position, or both, relative to the boundary of the factory or company that they live in or nearby. Contemporarily, it was a fact that people would choose a job mostly for geographical reasons, especially in the early stages of domestic company development. This was because commuting costs occupied a majority of the employee's total costs, considering the low wage earned, low public awareness of the product, and little profit gained. It was treated as an opportunity cost for the long time wasted waiting with nothing gained. Later, with bigger factories or premises, especially in big cities, workers dispersed geographically because of the large scale and complicated structure of the company. Then, it would be hard to know where a person was at a specific time, but it could be predicted with extremely high probability (as explained by the quantum mechanics theory). Wherever a person was, values would be added because human resources were important in initial entrepreneurship. If the factory was compared to the nucleus (the black point in the middle), while humans were electrons (the bright white dots surrounding the nucleus), the location of people would correspond to a picture shown in Figure 1, which is called the human-value model. The company, as the core asset of the entity, was in the middle of the illustration, while humans were spread around in any position, whether they were working in or outside the company, even resting or relaxing. In higher probability, they would appear nearer the core with a shorter distance, so the high density resulted in a bright view without almost any gaps around the middle point.

The human-value model exists because human workers or employees are the basic units of the organization and are widely distributed. They work for the entity ordinarily but in different channels and in different working positions. Humans add value, being active and willing to move to make the change, and so are capital resources of value and profit, responsible for the survival and development of the organization. Therefore, most economic activities, including purchasing, manufacturing, or marketing, can be regarded as chemical reactions if entities are treated as molecules while the interaction of humans is considered as electron transfer between atoms. 


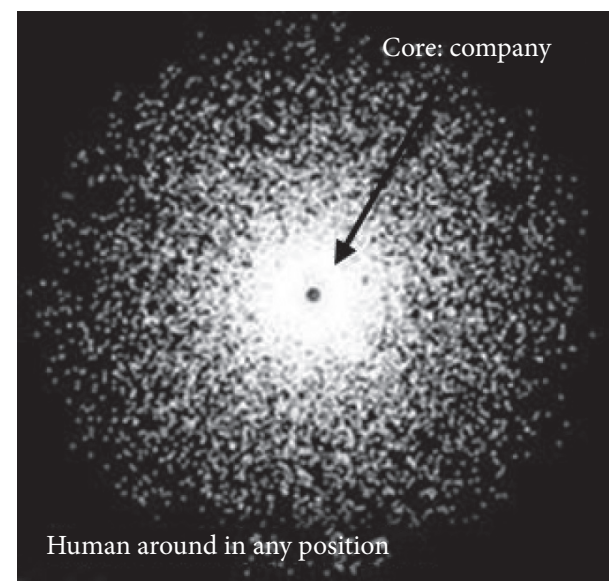

Figure 1: Company-human relationship, based on the electron cloud model (human-value model).

4.2. Expanding Stage: Market and Product. In the later stages of domestic company development, factories develop to become large-scale, and companies tend to expand abroad with a specific representative of their own. This is the product, especially an end product with a brand reputation. Trade is a primary way of internationalization, according to the OLI model developed by Dunning. In a specific market, especially a foreign market, the company is usually known by its product and, again this situation, can be similarly elaborated by the electron cloud model with the nucleus of the company making a product and the electron of a human consuming that product. However, this time the consumer, not the worker, is the human electron in the global view.

In a foreign market, the key distribution channel for new products relies on factory shops, outlets, franchises, chain stores, and supermarkets. Few workers, except employees in marketing or sales, go abroad, while most of them are domestically based. Different types of retailers directly serve consumers of different ages, income levels, social classes, consumptive habits, and other different influencing factors. Large volume retailers such as outlets and supermarkets usually cover largely populated areas, leading to effective advertising and marketing. However, for the reason of geographical asymmetry and socially unbalanced development, the model of product distribution tends not to be a spherical shape in the expanding stage, as shown in Figure 1.

4.3. Internet Age: An Exact Model. Now, we are living in the Internet age and a world of globalization with complicated labor division and industrial integration. The new technology of communication and information has made the world globally connected, where companies and entities are inclined to be international organizations. With different e-commerce platforms, mobile apps, and websites, any product or service can be reached through the Internet, and latterly, the internet of things. The influence of the company, along with its products or services, has spread widely without geographical barriers or conditions, and mobile Internet access has reconstructed social classes and made them more balanced than ever before mentioned above in
Section 4.2. As a result, the analysis of the market-andproduct relationship distribution above has finally turned into a symmetrically spherical one, as in Figure 1. The international consumer model is still the electron cloud with the company as its nucleus and humans as electrons, but it now represents a model from the macro global perspective instead of just a limited specific domestic market in Section 4.1 .

\section{International Corporation Evolution}

Billions of chemical reactions happen every day, including biological reactions, based solely on electron transfer. So is the case with human society because billions of people are involved in the global economy through daily life and work, which supports the fact that humans are the basic active unit of a company or entity, just as electrons are to atoms and molecules. Therefore, the model described above turns out to be unified whether humans are workers for the company or consumers of the product because workers may add value just by trading, selling, and working with other humans, such as suppliers, consumers, or dealers as value exchange agents. In the mobile Internet era, all humans are trying to make contact and trade with other people by we-media, without considering what organization they belong to. This may be the essence of the human-electron analogy, leading to a new form of organizational structure. The model of company evolution is to feature the changing process, relating companies to humans.

5.1. Company-Atom Analogy. Companies differ concerning their actual scale according to the number of humans they employ. In the process of evolution using the theory of the product life cycle [30], it is clear that the number of humans increases with the development and internationalization of a company, from a domestic unknown to a global corporation.

In the proposed model, if humans were compared to electrons, then companies could be treated as atoms. In classic chemistry, atoms are the smallest fundamental constituent unit of any ordinary matter with the properties of a chemical element. Atoms are composed of a nucleus, which is made of protons and typically a similar number of neutrons, while electrons are orbiting the nucleus. The number of protons in the nucleus defines what element the atom is named chemically, while the number of neutrons defines the isotope, and the number of electrons influences the magnetic and natural properties of an atom. With similar characteristics in modern society, companies are a constituent unit of the economy and are composed of entities such as the nucleus, which is made of assets and capabilities, and humans are like the electrons bound to the entity. Assets are anything that produces value, whether tangible or intangible, that can be owned or controlled as a concrete core. These are held by a company or an entity as a fixed part to produce positive economic value, similar to protons. Humans, on the other hand, play a critical role as an abstract resource of surplus value and are an active part with a loose affiliation to the company, which are the same as electrons. 
Humans as staff and employees rely on assets and produce value but are not connected tightly or permanently for reasons of possible dismissal and resignation. The common resources of raw and processed materials, technologies, working expertise and skills, and managerial patterns can all be shared and do not add direct value. These define the specific industry diversification to which a company belongs and act as neutrons. It is well-established that the companyatom analogy based on the natural structure of an atom possesses many similarities to a company in human society.

According to Marx's economic theory, "surplus value is equal to the new value created by workers in excess of their own labor cost." Humans are a direct resource of value with creative innovation and labor, can be measured by wages or salary paid, and are seen to be a form of money. Assets and capability are also a resource of value with the potential or established entity; they can be assessed in transactions and are also recognized as a form of money in a commercial society. Just as protons and electrons can be unified in physics as charged particles with different positive or negative charges and their flows showing in the form of energy, assets and humans can also be unified as a form of capital with an inactive or active nature and assessed in the form of money.

In the analogy above, companies in different industries can be treated similarly by considering their volume and scale, that is, companies of different industries are like the isotopes of an element. Also, an industry, like a molecule, is constituted of different companies like elements or atoms according to an industrial chain. This model may help describe the social-economic structure in the view of chemical atom-based combination. The following section focuses only on the economic scale evolution of the company.

\subsection{Company: Organization Type and Differentiation. In} chemistry, a tabular arrangement of all the elements ordered by atomic number with electron configurations, called the periodic table, is widely used to show recurring periodic properties and trends, especially elements with similar behavior in the same "column." It is believed that a company organization evolves with its economic scale. With its initial low profitability and low possibility of survival, no company can afford large human resource expenditure during the start-up phase, reflecting the fact that small companies employ few people, who may be ready to resign anytime. Companies with a larger economic scale tend to hire more people, developing like a snowball with a definite pattern of profitability, more money earned, more assets secured, and more employees hired, as a cycle. It can be illustrated that the classic structure of atoms with energy stability can be compared to the status of a company, with subshells equivalent to management levels, as shown in Table 1.

Hydrogen, with the symbol $\mathrm{H}$ and atomic number 1, is the lightest element in the periodic table and is also known as the most abundant chemical substance in the universe, constituting roughly $75 \%$ of all baryonic mass.

The H-type company usually refers to a self-employed individual or a person who is currently not working, having recently graduated from college, or resigned from a company. In this type of structure, the individual usually has two options: join another company to act as an electron with the company acting as a void hydrion or adding another person to form a small company as a locally owned business, such as a convenience store.

Helium, which has the symbol He and an atomic number of 2 , is the first element in the noble gas column in the periodic table. It is the second lightest and second most abundant element in the observable universe, being present in about $24 \%$ of the total elemental mass. It is known for its simple structure and stable nature.

A He-type company is the simplest company, consisting of two people, such as two siblings, two friends, or a married couple. It is local but highly stable due to the relationship between the partners being so complementary. The scale and scope of business are limited and scarcely profitable with its simple general business and low demand from the small population such as a community or village, intending to meet consumer needs for a limited geographical area.

The next element is lithium, with the symbol $\mathrm{Li}$ and atomic number 3. It is a soft, highly reactive, and flammable chemical element that is the lightest metal and the lightest solid element. The nucleus of its atom verges on instability, but it is still the first solid form in the periodic table.

The Li-type company represents a company with more people than the simplest He-type form or the H-type individual. With examples such as children unwilling to inherit a mom-and-pop store and more workers employed by a larger-scale company, they tend to be treated as an outsider, far from core management and decision-making but usually talented, educated, skilled, or creative with high energy and innovation. They act as the outer shell electron while the remaining two electrons are in the $1 s$ orbital path with much lower energy, maintaining stability, and not participating in chemical bonds. However, few such businesses of this type exist, making them as rare as lithium is in the universe. It is usually a transitional stage as more people, not only one or two, will often be employed to transform it into a formal organization with a larger scale.

Carbon is a nonmetallic and tetravalent element, making four electrons available to form structures called covalent chemical bonds. It has the symbol $\mathrm{C}$ and atomic number 6 , and it is the fourth most abundant element in the universe by mass after $\mathrm{H}, \mathrm{He}$, and oxygen $(\mathrm{O})$. The huge abundance of carbon, the structural diversity of organic compounds it forms, and its unusual natural ability to form polymers at the ambient pressure, gravity, and temperature commonly encountered on Earth enable this element to serve as the most common structural and functional element of all known life. The atoms of carbon can bond to each other in different ways, and these ways are termed the allotropes of carbon.

C-type companies are the most common form of any company with an entrepreneurial team, just as carbon is regarded as the most popular element in nature. The physical properties of carbon vary sharply with the allotropic form, for example, graphite is soft, but diamond is the hardest known naturally occurring material. Also, this form of variable flexibility seems to fit companies well for their 
TABLE 1: Comparison of some classic structures of atoms and companies.

\begin{tabular}{|c|c|c|c|c|c|}
\hline \multicolumn{3}{|c|}{ Atom } & \multicolumn{3}{|c|}{ Company } \\
\hline $\begin{array}{l}\text { Name and } \\
\text { symbol }\end{array}$ & $\begin{array}{l}\text { Number of } \\
\text { electrons }\end{array}$ & $\begin{array}{l}\text { Electron orbiting } \\
\text { configuration }\end{array}$ & $\begin{array}{c}\text { Number of } \\
\text { humans (type) }\end{array}$ & Typical organization & Characteristics \\
\hline Hydrogen $(\mathrm{H})$ & 1 & $1 s^{1}$ & 1 (H-type) & $\begin{array}{l}\text { Self-employed } \\
\text { individual }\end{array}$ & Job hunting \\
\hline Helium (He) & 2 & $1 s^{2}$ (saturated) & 2 (He-type) & $\begin{array}{l}\text { General store, } \\
\text { "mom-and-pop" } \\
\text { store }\end{array}$ & $\begin{array}{c}\text { Simple general business } \\
\text { with a limited geographical } \\
\text { area }\end{array}$ \\
\hline Lithium (Li) & 3 & $1 s^{2} 2 s^{1}$ & 3 (Li-type) & $\begin{array}{l}\text { Transitional stage to } \\
\text { micro-enterprise }\end{array}$ & $\begin{array}{c}\text { Entrepreneurial stage (local } \\
\text { recruitment) }\end{array}$ \\
\hline Carbon (C) & 6 & $1 s^{2} 2 s^{2} 2 p^{2}$ & 6 (C-type) & Micro-enterprise & $\begin{array}{l}\text { Entrepreneurial stage (stable } \\
\text { period) }\end{array}$ \\
\hline Oxygen (O) & 8 & $1 s^{2} 2 s^{2} 2 p^{4}$ & 8 (O-type) & $\begin{array}{l}\text { Micro-enterprise } \\
\text { (branch store) }\end{array}$ & $\begin{array}{c}\text { Entrepreneurial stage (local } \\
\text { expansion) }\end{array}$ \\
\hline Neon $(\mathrm{Ne})$ & 10 & $1 s^{2} 2 s^{2} 2 p^{6}$ (saturated) & 10 (Ne-type) & $\begin{array}{l}\text { Small- or medium- } \\
\text { sized enterprise }\end{array}$ & $\begin{array}{l}\text { Middle-scale with simple } \\
\text { and clear hierarchy }\end{array}$ \\
\hline Sodium $(\mathrm{Na})$ & 11 & $1 s^{2} 2 s^{2} 2 p^{6} 3 s^{1}$ & 11 (Na-type) & $\begin{array}{l}\text { Small- or medium- } \\
\text { sized enterprise }\end{array}$ & $\begin{array}{c}\text { Growth stage (cross-border } \\
\text { expansion) }\end{array}$ \\
\hline Uranium (U) & 92 & $\begin{array}{c}1 s^{2} 2 s^{2} 2 p^{6} 3 s^{2} 3 p^{6} 3 d^{10} 4 s^{2} 4 p^{6} 4 d^{10} 4 f^{4} \\
5 s^{2} 5 p^{6} 5 d^{10} 5 f^{3} 6 s^{2} 6 p^{6} 6 d^{1} 7 s^{2}\end{array}$ & 92 (U-type) & $\begin{array}{c}\text { Multinational } \\
\text { enterprise }\end{array}$ & Bureaucratic stage \\
\hline
\end{tabular}

survival and development in the early entrepreneurial stage. The nature of carbon originates from its electron distribution: two stable electrons with low energy inside in the $1 s$ orbital, but four valence electrons of which two are in $2 s$ and the rest are in the $2 p$ orbital. These have higher energy and can participate in the process of forming different chemical bonds, either removing the extra valence electrons to form a positive ion, gaining electrons to form a negative ion, or sharing valence electrons to form a covalent bond. As for the C-type company, if two people constitute the core management and decision layer like in the $1 \mathrm{~s}$ orbital, the combinations of the remaining four people within the outer shell vary widely. These four people, as the operators, can choose to leave, resulting in a Li-type company; alternatively, someone else could be hired, forming the structure of an O-type company; or they could share their time working in a part-time job. One or two of the employees in the $2 s$ orbital could be junior managers, working to expand the business and leading this type of business to be more diversified. It would be temporally stable and flexible in the long term and is a vivid example of a small company with a larger scale in its start-up phase.

Oxygen, with the symbol $\mathrm{O}$ and atomic number 8 , is a highly reactive nonmetal chemical element. It is an oxidizing agent that forms oxides with most elements and compounds and is the third-most abundant element in the universe by mass. Structurally, this element makes up almost half of the Earth's crust. As it is a component of water, most of the mass of living organisms is oxygen, resulting in it being the major constituent of the biological functions of life forms.

The O-type company tends to describe the transitional structure of a company willing to grow with more and more people employed before becoming a large formal company. It represents a company that is active, changing, living, and blooming. The company is trying to find new items of business and expand potentially profitable fields with a stronger will and more stable core management than a
C-type company. Just as the shape of the $2 p$ orbital is like a dumbbell in three dimensions (as shown in Figure 2), branch stores appear in other areas geographically with several newly employed or appointed managers. This time, the $2 s$ orbital people act as managers of the initial store or parent company, while the $1 s$ orbital people remain as the solid core management and decision layer for the whole organization.

Next to oxygen is neon, with the symbol $\mathrm{Ne}$ and atomic number 10. It is a chemically inert noble gas and a very common element in the universe and the Solar System, being fifth in cosmic abundance after $\mathrm{H}, \mathrm{He}, \mathrm{O}$, and $\mathrm{C}$.

Ne-type companies are formal and stable, with complete management systems and profitability. This type of company is usually a middle-scale domestic entity with a simple and clear hierarchy. However, this is not the end of the evolution of the company, for its stability relies on a simple financial ecosystem with limited governance and without expansion abroad. It is not very competitive compared with other larger companies, especially in these times of globalization. Every company operates in an uncertain and dynamic environment, which is shown by a full outer orbital path for the atom. The analogy for companies is that of different ecologies such as religion, culture, societal behavior, or legal system.

Sodium has the symbol $\mathrm{Na}$ and an atomic number of 11 . It is known for being a soft, highly reactive metal, and it has a single electron in its outer shell $3 s$. It readily donates this electron, resulting in a positively charged ion, the $\mathrm{Na}^{+}$ cation, forming the simple extroverted type.

The Na-type company stage is the first stage of a company trying to expand abroad, with unspecified risks. The element after sodium in the periodic table seems to describe the long process of expanding across borders with different expansion strategies such as international, multinational, or global strategies. Assets have been accumulated on an even larger scale, and more people are employed worldwide with manufacturing and business expansion. The distribution of business, entity, and subsidiary also varies 


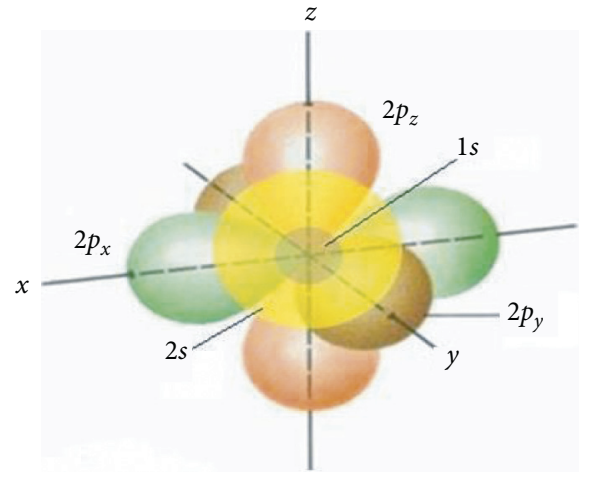

FIGURE 2: Electron distribution simulation of an atom (orbits 1 and 2).

sharply as electron orbitals, with the spherical $s$ shape, dumbbell-like $p$ shape, petal-like $d$ shape, and more complicated shapes for $f$ and the others.

Most companies, especially multinational or global ones, are in a state of continuous expansion. It can be demonstrated by the model here that in the periodic table, the element after sodium follows the analogy. The scale of the assets is larger, and there are more employees with various combinations of skills and expertise. Similar to a larger atom with a higher atomic weight, it can usually be observed that larger companies have higher resignation rates, just like electrons leaving an atom temporarily or permanently.

The final element in the list is uranium, which has the symbol $U$ and an atomic number of 92 . It is a metal element with 92 electrons, of which 6 are valence electrons. Uranium is weakly radioactive with all of its isotopes being unstable, and it has the highest atomic weight of the naturally occurring elements on Earth.

A U-type company symbolizes the modern trend of extremely large-scale global corporations, which is that a large company faces the potential situation of disintegration or is divided into several smaller companies. It is observed in nature that atoms of high energy levels tend to be unstable. Something similar can be seen with companies, especially global corporations with huge bureaucracy and a strict hierarchy.

\subsection{Supplementary Explanation of Humans and Companies.} In the chemical theories developed from laboratory experiments and measurements, a valence electron is an electron in the outer shell associated with an atom. It can participate in the instant process of forming chemical bonds if the outer shell is not "closed." In a typical single covalent bond, both atoms contribute one valence electron to form a shared pair, not gaining or losing. The status of valence electrons can determine the chemical properties of an element, for its valence shows how readily and with how many other elements it may bond with. In the periodic table, atoms with only one or two valence electrons to be gained or lost to become a "closed" shell are highly reactive because it requires relatively low energy to remove the extra valence electrons to form a positive ion or to gain to form a negative one. It is their tendency either to gain or lose an electron in a process called ionization with electron transition and spontaneous energy flow or to share valence electrons naturally.
In this analogy, when a start-up company develops, an appropriate description of the structure is that humans gather and function well in a specific geographic area. Still, it is a complicated process when the company begins to grow and expand abroad to become an international business. Local differences have posed problems for different cultures, religions, regulations, and rules, as well as consumer behavior and preferences. However, if these are reconsidered in another generalized view, society and civilization depend highly on a basic unit, which is human.

Humans play a similar role to electrons due to their social character and more complicated mechanism. The companyatom analogy highlights the organizational structure, visually solving the unpredictable probability when employees are working. It describes the relative position between the employees and the geographically stationary company in the mobile Internet era, where a flexible organization for collaboration, work arrangements, and contingent workforce prevail. Additionally, from a quantum mechanics perspective, people are all nodes with energy (electrons) in the network of human society, and the network constitutes the form of quantum organization. The attitudes of humans, not only employers but also managers and even shareholders of a specific company, will be changeable, and humans are bounded rational by different motivations or cognitive limitations. Whether someone chooses to join or leave a company or to get a parttime job and share themselves with another company partially depends on the scale and operational situation of a company. However, people are inclined to assemble and accumulate to an acceptable proper volume because human beings are socially connected and recognize the costs of gathering and processing information that relies highly on casual information exchange, local community, and public companies. There is another trend that occurs because larger companies usually offer better positions with higher pay, more promising careers, and a better reputation based on accumulated assets. This attracts more people and the company grows even larger as with a snowball rolling process. All of these can be summarized as the connecting and sharing for hints naturally above.

There is a long list of elements in the periodic table between sodium and uranium, and the international expansion of companies is also a long process. By not using the actual number of electrons to be equal to the number of people in a company, the range reveals not only the change of scale but also the diversification of strategic approaches. It fits the theory of orbital hybridization in chemistry that organizational structure changes when expanding abroad and that the informationsharing ability of employees and customers within a blurred boundary, especially in the mobile Internet age with worldwide connection, becomes easier. Connection seems to be a spontaneous result, whether in human society or in natural world.

\section{Discussion of Company Organization Evolution}

6.1. Evolutionary Process. Above all, this model is trying to reason that the quantum interconnects into a network using quantum entanglement, and the quantum (human or electron) becomes a node in the network. Each human is a 
node connected to our civilization network, instead of the traditional hierarchy theory focusing on command and control of the people in an organization.

In this model of company type differentiation derived from the elements, only typical atoms were elaborated upon, while the cycle actually runs from small to large with alternate but progressive "instability-stability-instability" in the periodic table. Typically, stable elements such as He and $\mathrm{Ne}$ work as a scaled boundary of the company, forming three zones: geographically local before He-type, then domestic until Ne-type, and later becoming international. In atom theory, electron shells and subshells operate as the boundaries. In the social economy, companies progress from a limited local area to a formal domestic entity, then to an international company expanding abroad. This evolution also stresses the scale expansion and asset accumulation with measurable social energy of capital.

Under the specific one-shell model of a limited number of people working for a local business, a balance is kept between supply and demand in a small area with a local social network in the community. For its geographically limited range, it covers the area effectively and operates steadily.

With the two-shell model of a domestic company, a more formal setup is required with more managers possessing basic levels of administrative experience. Several entrepreneurs constitute the core management as the inner shell, responsible for future planning and decision-making, while the outer shell is for business and operation. More management levels are established with more people hired in the outer shell, while the inner shell may select a board of directors, introduce shareholders, and gradually form a reasonable bureaucratic system for rigorous management.

In the multishell model of the international organization, there are signs of complicated mechanisms and strategies to fit worldwide diversity and sustainable globalization. As the outer shell electron cloud can appear in different shapes, companies should establish specific intricately detailed structures to achieve local responsive flexibility, global integration, and coordination, combined with worldwide innovation and learning. The electron cloud of the atom shows the probability of the location of the electron and human economic activities as well. Therefore, the multidimensional extension of the electrons in the $p$ orbital (shown in Figure 2) may be a suitable model for multinational companies. This is because this type of allocation with local subsidiaries responds well to local markets and does not affect each other as the center of gravity for the dumbbell shape lies in the end. The highly symmetrical spherical shape of electrons in the $s$ orbital may be a suitable model for a global company because highly standardized strategies demand coordinated services or products for the global market without significant differences. The differences when moving from the inner to the outer shell describe the similar diffusion of innovation and learning that is adopted by most international companies. Just as the electron cloud shows complex variations for the elements after sodium in the periodic table with $d$ or $f$ orbitals, transnational companies should try to establish interdependent integrated network structures to solve the conflicting flexibility, integration, and innovation simultaneously. There may be even more complicated mechanisms for the social economy, leading to four or more dimensions in the electron cloud model being considered.

Another indication from the nature of the atom is that the number of neutrons is usually similar to the number of protons. In the reasoning above, neutrons add no direct value but define specific industry diversification; therefore, they should match the "proton asset scale." A better explanation is that they could represent the managerial system, business mode diversification, and expertise improvement evolution for an international corporation.

6.2. Companies and Globalization: Sharing More. All that has been mentioned mostly discusses the detailed model of the evolution of one company from a small business to a global corporation, emphasizing its organizational structure. But the global economy is not composed of only one company, and the same can be said that the world is not composed of only one atom. Compounds and molecules, composed of combinations of atoms, undergo chemical reactions that are mostly related to electron flows, while the global economy is sustained among companies through trades and transactions mostly related to capital flow. The company-atom analogy focuses on the specific structure of a company with its core management, but it still works in the broader perspective to explain the combination of differently owned companies as strategic alliances, through licensing or foreign direct investment, among which humans play the roles as that of electrons in chemical reactions.

From the observation of the recent transformative evolution of organizations, natural carbon has a unique structural diversity because four outer electrons are available to form covalent chemical bonds. With its core concept of sharing electrons adaptively, it is also true that individual values (quantum energy) depend on the degree to which they are connected, and the more they are connected or shared, the greater their value. Humans are the most active factor in a quantum-like organization compared to other resources.

In the twenty-first century, the Internet age has provided a boundless world for all companies and has influenced their structural evolution. Mobile technology has made the world connected. At the same time, it has led to global sustainability with new flexible forms of connection among people or stakeholders of any company. It has allowed for the sharing of information, eliminating the traditional gaps created by information asymmetry in supply and demand, and also operation and administration. This is especially true in certain countries with huge populations and many smartphone consumers such as China and India. In the mobile Internet era, anybody can connect to the web easily, and connected companies are facing a completely different market with a diverse customer base. Considering that people tend to make bounded rational decisions to satisfice, although these global customers possess different behaviors, cultures, and languages, they all have tremendous amounts 
of information, open channels of worldwide distribution, and the same preference for internet-style sharing and easy self-expression. International companies may work as a single atom, but their structures have evolved and improved and are often combined with other ones just as there are few pure substances made of single atoms in nature. Some companies are born global with their business models, but those that are not global often choose to transition into a boundaryless organization, strategic alliance, or virtual enterprise. This is because management models with a rigid hierarchy and strong command do not fit the modern structure. All of these emerging organizational phenomena could be explained by the model above for the "connection and sharing" found in both nature and society.

\section{Conclusions}

Companies are facing the fact that global sustainability will depend on economic development balanced with resource constraints and population growth in the coming years. Digitalization eliminates the boundaries between nations, religions, and even cultures with more people from different civilizations using mobile devices to communicate and share. However, these people also have an uncertain and dynamic location, thus influencing organizational transformation. This paper fulfills a comparative study on what leads to organizational change and how economic activities influence it from interdisciplinary perspectives to describe structural evolution and its mechanisms. Inspired by the natural theory of atoms and the methodology of quantum mechanics, a model was developed to analyze corporate organizational structural differences and evolution in human society, for further insight into global economic sustainability in the mobile Internet era. Based on the analogy between humans and electrons, it is apparent that companies and atoms function according to a similar structural model. This has led to the organizational theory being applied to entities in the new mobile Internet era focusing on connecting and sharing among people.

It is expected that more empirical analysis of specific companies based on data or reports should be studied to test the new model so that this theoretical system can be further developed.

\section{Data Availability}

Data sharing is not applicable to this article as no new data were created or analyzed in this study.

\section{Conflicts of Interest}

The author declares that there are no conflicts of interest in this paper.

\section{References}

[1] Y. Liu, D. Liu, and Y. Chen, "Research on sentiment tendency and evolution of public opinions in social networks of smart city," Complexity, vol. 2020, no. 7, 13 pages, Article ID 9789431, 2020.
[2] E. Z. Berglund, J. G. Monroe, I. Ahmed et al., "Smart infrastructure: a vision for the role of the civil engineering profession in smart cities," Journal of Infrastructure Systems, vol. 26, no. 2, Article ID 03120001, 2020.

[3] C. Lamberton and A. T. Stephen, "A thematic exploration of digital, social media, and mobile marketing: research evolution from 2000 to 2015 and an agenda for future inquiry," Journal of Marketing, vol. 80, no. 6, pp. 146-172, 2016.

[4] M. Hendijani Fard and R. Marvi, "Viral marketing and purchase intentions of mobile applications users," International Journal of Emerging Markets, vol. 15, no. 2, pp. 287-301, 2019.

[5] S.-P. Jun and D.-H. Park, "Consumer information search behavior and purchasing decisions: empirical evidence from Korea," Technological Forecasting and Social Change, vol. 107, pp. 97-111, 2016.

[6] J. I. Galan and J. Gonzalez-Benito, "Distinctive determinant factors of Spanish foreign direct investment in Latin America," Journal of World Business, vol. 41, no. 2, pp. 171-189, 2006.

[7] P. Gomber, R. J. Kauffman, C. Parker, and B. W. Weber, "On the fintech revolution: interpreting the forces of innovation, disruption, and transformation in financial services," Journal of Management Information Systems, vol. 35, no. 1, pp. 220265, 2018.

[8] S. Stieglitz and T. Brockmann, "Increasing organizational performance by transforming into a mobile enterprise," MIS Quarterly Executive, vol. 11, no. 4, pp. 189-204, 2012.

[9] A. Verbeke, "The evolutionary view of the MNE and the future of internalization theory," Journal of International Business Studies, vol. 34, no. 6, pp. 498-504, 2003.

[10] J. H. Dunning, "Toward an eclectic theory of international production: some empirical tests," Journal of International Business Studies, vol. 11, no. 1, pp. 9-31, 1979.

[11] J. H. Dunning, "The eclectic paradigm of international production: a restatement and some possible extensions," Journal of International Business Studies, vol. 19, no. 1, pp. 1-31, 1988.

[12] J. H. Dunning, "The eclectic paradigm as an envelope for economic and business theories of MNE activity," International Business Review, vol. 9, no. 2, pp. 163-190, 2000.

[13] P. J. Buckley, A. R. Cross, H. Tan, L. Xin, and H. Voss, "Historic and emergent trends in Chinese outward direct investment," Management International Review, vol. 48, no. 6, pp. 715-748, 2008.

[14] S. A. Fernhaber, B. A. Gilbert, and P. P. Mcdougall, "International entrepreneurship and geographic location: an empirical examination of new venture internationalization," Journal of International Business Studies, vol. 39, no. 2, pp. 267-290, 2014.

[15] H. P. Gray, Extending the Eclectic Paradigm in International Business: Essays in Honor of John Dunning, Edward Elgar Publishing, Cheltenham, UK, 2003.

[16] K. Wadhwa and R. S. Sudhakara, "Foreign direct investment into developing Asian countries: the role of market seeking, resource seeking and efficiency seeking factors," International Journal of Business and Management, vol. 6, no. 11, pp. 219-226, 2011.

[17] J. M. Stopford and L. T. Wells, Managing the Multinational Enterprise: Organization of the Firm and Ownership of the Subsidiaries, Basic Books, New York, NY, USA, 1972.

[18] C. A. Bartlett and P. W. Beamish, Transnational Management: Text, Cases and Readings in Cross-Border Management, Cambridge University Press, Cambridge, UK, 8th edition, 2018. 
[19] C. A. Bartlett and S. Ghoshal, "Matrix management: not a structure, a frame of mind," Harvard Business Review, vol. 68, no. 4, pp. 138-145, 1990.

[20] K. W. Abbott, J. F. Green, and R. O. Keohane, "Organizational ecology and institutional change in global governance," International Organization, vol. 70, no. 2, pp. 247-277, 2016.

[21] T. L. Amburgey and H. Rao, "Organizational ecology: past, present, and future directions," Academy of Management Journal, vol. 39, no. 5, pp. 1265-1286, 1996.

[22] M. Riviere, A. E. Bass, and U. Andersson, "Dynamic capability development in multinational enterprises: reconciling routine reconfiguration between the headquarters and subsidiaries," Global Strategy Journal, vol. 11, no. 3, pp. 380-401, 2021.

[23] J. H. Dunning and S. M. Lundan, "Institutions and the OLI paradigm of the multinational enterprise," Asia Pacific Journal of Management, vol. 25, no. 4, pp. 573-593, 2008.

[24] J. Cantwell, J. H. Dunning, and S. M. Lundan, "An evolutionary approach to understanding international business activity: the co-evolution of MNEs and the institutional environment," Journal of International Business Studies, vol. 41, no. 4, pp. 567-586, 2010.

[25] A. Museli and N. Jafari Navimipour, "A model for examining the factors impacting the near field communication technology adoption in the organizations," Kybernetes, vol. 47, no. 7, pp. 1378-1400, 2018.

[26] N. Rozanova, "Evolution of a firm in a digital economy," World Economy and International Relations, vol. 63, no. 8, pp. 21-28, 2019.

[27] J. A. Simpson and E. S. C. Weiner, Oxford English Dictionary, Clarendon Press, Oxford, UK, 2nd edition, 1989.

[28] M. Born, "Atomic physics," Dover Books on Physics and Chemistry, Dover Publications, New York, NY, USA, 8th edition, 1989.

[29] K. Shi, "Eco-city: a living organism system," Advanced Materials Research, vol. 616-618, pp. 1280-1284, 2013.

[30] T. Levitt, "Exploit the product life cycle," Harvard Business Review, vol. 43, no. 6, pp. 81-94, 1965. 